\title{
LOKA: RUMPUN TERINTEGRASI KULTUR DAN AGRARI
}

\author{
Ruthchan ${ }^{1)}$ \\ 1)Program Studi S1 Arsitektur, Fakultas Teknik, Universitas Tarumanagara, \\ ruthchan.315170064@stu.untar.ac.id
}

Masuk: 04-07-2021, revisi: 14-08-2021, diterima untuk diterbitkan: 23-10-2021

\begin{abstract}
Abstrak
Dunia sudah mengenal Bangka Belitung sebagai penghasil timah terbanyak kedua di dunia dengan kualitas timah terbaik. Namun, lahan pasca tambang timah didominasi oleh hamparan tailing dan kolong yang memiliki karakteristik fisika dan kimia tanah, serta kondisi iklim mikro yang buruk. Adanya pertambangan timah yang merajalela juga menyisakan permasalahan secara ekonomi, sosial dan ekologi ditengah masyarakat Bangka. Menggunakan metode penelitian kualitatif dengan memperhatikan kualitas desain dari metode kolase, Loka: Rumpun Terintegrasi Kultur dan Agrari adalah sebuah kawasan untuk masyarakat local sendiri berkumpul, bekerja, dan bermain. Proyek ini bertujuan untuk dapat memunculkan kembali rasa kagum manusia terhadap alam dan bangunan seakan membantu alam untuk mengambil alih apa yang semula miliknya. Kawasan ini berlaku sebagai medium untuk memulihkan keadaan sosial, ekonomi dan ekologi yang terdampak selama adanya pertambangan timah. Kawasan ini diharapkan dapat menghidupkan kembali kedinamisan dan vitalitas daerah.
\end{abstract}

Kata kunci: ekologi; ekonomi; memulihkan; sosial; timah

\begin{abstract}
The world already knows Bangka Belitung as the second largest producer of tin in the world with the best tin quality. However, the post-tin mining area is dominated by tailings and pits which have physical and chemical characteristics of the soil, as well as poor microclimate conditions. The existence of rampant tin mining also leaves economic, social and ecological problems among the people of Bangka. Using qualitative research methods by paying attention to the design quality of the collage method, Loka: Cluster Integrated Culture and Agrarian is an area for local people to gather, work, and play. This project aims to be able to bring back the human admiration for nature and buildings as if helping nature to take over what was originally hers. This area acts as a medium to restore social, economic and ecological conditions that were affected during the tin mining. This area is expected to revive the dynamics and vitality of the region.
\end{abstract}

Keywords: ecology; economic; revive; social; tin

\section{PENDAHULUAN \\ Latar Belakang}

Dunia sudah mengenal Bangka Belitung sebagai penghasil timah terbanyak kedua di dunia dengan kualitas timah terbaik. Dengan luas Kepulauan Bangka Belitung 1,6 juta hektar, 3/4 dari luas wilayahnya masuk dalam Izin Usaha Pertambangan (IUP) skala besar maupun inkonvensional. Aktivitas tambang timah di lahan seluas itu menyebabkan 62\% lahan di Bangka Belitung merupakan lahan kritis (WALHI, 2017). Pulau Bangka sendiri luasnya mencapai 1.294.050 HA, 27.56\% daratan pulaunya merupakan area Kuasa Penambangan (KP) timah (Hotimah, 2015). Dalam sejarahnya, daerah yang sekarang disebut Kecamatan Muntok adalah daerah pertama adanya penambangan timah berlubang besar pada tahun 1733 oleh penambang-penambang tionghoa (Muhammad, nationalgeographic.grid.id/read/132449723, 
2020). Sejarah panjang pertambangan timah di Muntok, menyebabkan terbukanya lahan-lahan yang disebut kolong yang ditinggalkan begitu saja.

Dampak dari operasi penambangan adalah penurunan sifat-sifat fisik dan kimia tanah, perubahan topografi lahan, hilangnya vegetasi alami, berkurangnya habitat satwa liar, dan dengan begitu merusak ekosistem yang ada. Lahan pasca tambang timah didominasi oleh hamparan tailing dan kolong. Kolong memiliki karakterisitik fisika dan kimia tanah, serta kondisi iklim mikro yang buruk. Untuk memanfaatkan kembali lahan pasca tambang timah, terutama lahan tailing perlu dilakukan reklamasi dan rehabilitasi (Asmarhansyah, 2017). Berbagai aplikasi teknologi telah dan akan dikembangkan untuk memperoleh hasil yang memuaskan. Sejumlah spesies tumbuhan spesifik lokal, tanaman eksotik seperti akasia, dan tanaman budidaya dikembangkan sebagai tanaman untuk revegatasi lahan pasca tambang timah. Namun demikian sampai saat ini belum ada manfaat ekonomis yang secara nyata dirasakan oleh masyarakat dari reklamasi tersebut (Muhammad, nationalgeographic.grid.id/read/132449723, 2020).

Saat ini, bekas tambang inkonvensional kekurangan perhatian dan solusi oleh pemerintah setempat untuk melakukan pembenahan dan upaya pemanfaatan yang mendukung terhadap lahan yang rusak pasca pengoprasian tambang. Pembangunan yang ada sering kali menyebabkan kolong yang semula dimilikki rakyat menjadi dibatasi dan diperuntukkan untuk kepentingan tertentu, warga lokal sendiri seperti tidak mendapat apapun dari adanya pertambangan sampai menjadi kolong. Padahal, pembangunan berbasis ekologi dirasa tepat untuk pembangunan kembali kolong-kolong yang sudah terbengkalai di Muntok. Anjuran pemerintah, dalam RIPPDA Provinsi Kepulauan Bangka Belitung, menyatakan Muntok sebagai kawasan Pariwisata Sejarah dan Budaya, dapat direalisasikan kembali setelah sekarang seperti mengalami vakum. (RIPPARPROV Kep. Bangka Belitung 2016 -2025 , 2015)

Loka: Rumpun Agrari dan Kultur Terintegrasi adalah sebuah kawasan untuk masyarakat local sendiri berkumpul, bekerja, dan bermain. Proyek ini bertujuan untuk dapat memunculkan kembali rasa kagum manusia terhadap alam dan bangunan seakan membantu alam untuk mengambil alih apa yang semula miliknya. Kawasan ini berlaku sebagai medium untuk memulihkan keadaan sosial, ekonomi dan ekologi yang terdampak selama adanya pertambangan timah.

\section{Rumusan Permasalahan}

a. Bagaimana urgensi lahan tailing dan kolong pasca tambang timah terbengkalai menjadi bagian dari rencana?

b. Bagaimana dampak dari adanya lahan tailing dan kolong pasca tambang timah terbengkalai?

c. Bagaimana penerapan tema beyond ecology dapat menjadi solusi?

\section{Tujuan}

Dengan terbangunnya Rumpun Terintegrasi Kultur dan Agrari diharapkan mampu membangun kembali Desa Belo Laut, Muntok sebagai daerah yang lebih hidup dan maju, baik secara ekonomi, sosial, dan ekologinya. Kawasan ini juga bertujuan untuk memperbaharui kehidupan, cara berpikir, dan mimpi di tanah Bangka.

\section{Untuk Muntok}

Adanya kolong dan tailing pasca tambang menyebabkan Muntok seperti kehilangan daya tariknya karena sebagian besar lahannya sudah merupakan lahan mati yang kritis. Ekonomi daerah menurun akibat banyaknya warga lokal yang sebagian besar petani dan nelayan kehilangan pekerjaan. Loka: Rumpun Terintegrasi Kultur dan Agrari mencoba mengembalikan kesuburan tanah dan revitalisasi lahan pasca tambang timah sebesar-besarnya untuk 
kepentingan warga. Kawasan ini juga bertujuan untuk dapat menghasilkan sektor perekonomian yang baru bagi daerah Muntok.

\section{Untuk Komunitas}

Kultur masyarakatpun dipreservasi di Loka. Sebuah proyek agriwisata dan kultur yang tidak menyingkirkan warga lokalnya sendiri, namun menjadikannya tuan rumah. Komunitas petanim peternak, nelayan, warga lainnya, bahkan turis sama-sama diuntungkan. Upacara adat, acara warga, kumpul warga dapat diwadahi dan terintegrasi dengan tempat bekerja. Sebagai tempat rekreasi, wisata, yang dapat menghidupksn kembali Muntok yang sempat lesu.

\section{Untuk Masa Depan}

Pembangunan ini bukan hanya untuk membangkitkan ekonomi dan memakai apa yang seakan sudah tidak terpakai, tapi untuk mengembalikan apa yang sudah diambil dan menambahkannya. Pembanunan ini juga akan menambahkan value ke dalam sejarah panjang penambanan timah, membuka wawasan warga, dan shifting perspektif bahwa kolong bukan lagi luka yang menganga tapi sudah sembuh bahkan menghasilkan.

\section{KAJIAN LITERATUR}

Tema 'Melampaui' Ekologi Menuju Arsitektur Untuk Kebaikan dan Kehidupan adalah sebuah usaha untuk mempelajari kondisi kekinian sebuah ekosistem yang terjadi di bumi ini dan melihat bagaimana arsitektur dapat berperan dalam menghasilkan citra dan guna bagi masyarakat pemakainya. Kata 'melampaui' adalah sebuah ajakan untuk berani melakukan spekulasi dan eskperimental terhadap kondisi spatialitas dari ekosistem yang sedang dihadapi oleh bumi sekarang ini. Arsitektur yang melampaui ekologi adalah sebuah cara tetntang bagaimana arsitektur menampilkan kualitas spasial dengan dengan menempatkan posisi kompleksitas dan keunikan dari kondisi ekosistem yang ada di sekitarnya. (Pedoman Mata Kuliah Studio Perancangan Arsitektur 8.31, 2021)

Dalam menempatkan ekologi sebagai dasar dari sebuah design, harus menyediakan cara-cara yang spesifik dalam meminimalisir penggunaan energy dan material, mengurangi polusi, melestarikan habitat, dan merawat komunitas, kesehatan dan keindahannya. Dari pernyataan ini terdaapat 4 parameter yang menurut Van der Ryn adalah cara untuk membuat sebuah ecological design (Ryn \& Cowan, 2007):
a. Making nature visible
b. Everyone is a designer
c. Design with nature
d. Ecological accounting
e. Solutions grow from place

Stack (Platform of Digital Ecology), sebuah pemikiran dari Benjamin Bratton menyatakan bahwa Stack adalah nama untuk megastruktur tak disengaja dari komputasi skala planet dan merupakan cara untuk melihat struktur besar itu sebagai satu meta-teknologi. Alih-alih melihat sebagai jenis komputasi sebagai sekumpulan spesies komputasi yang berbeda, semuanya bergerak sendiri, kita dapat memahaminya sebagai bagian dari sesuatu yang besar. Membentuk komposit yang bentuk dan isinya tidak begitu berebda dengan perangkat lunak tumpukan perangkat keras. Ada lapisan modular dalam segala tumpukan yang masing-masing memiliki peran khusus untuk dimainkan dan masing-masin independen dan saling bergantung dalam hubungannya dengan lapisan lainnya. Ini bukan hanya masalah teknik karenakomputasi telah menjadi bentuk dan isi yang digunakan untuk mengatur ide, ekonomi, dan budaya kita. (Bratton, 2015) 


\section{Tambang Timah}

Penambangan timah terbagi menjadi beberapa jenis tergantung dari cara penambangan, diantaranya adalah penambangan timah lepas pantai dan penambangan timah darat. Penambangan lepas pantai dilakukan di laut (off shore) dengan mengoperasikan armada kapal keruk atau kapal hisap yang bekerja 24 jam sepanjang tahun. Kapal keruk berfungsi untuk menggali dan menghisap timah di dasar laut sampai dengan kedalaman 50 meter (Yulianti, Bani, \& Albana, 2020).

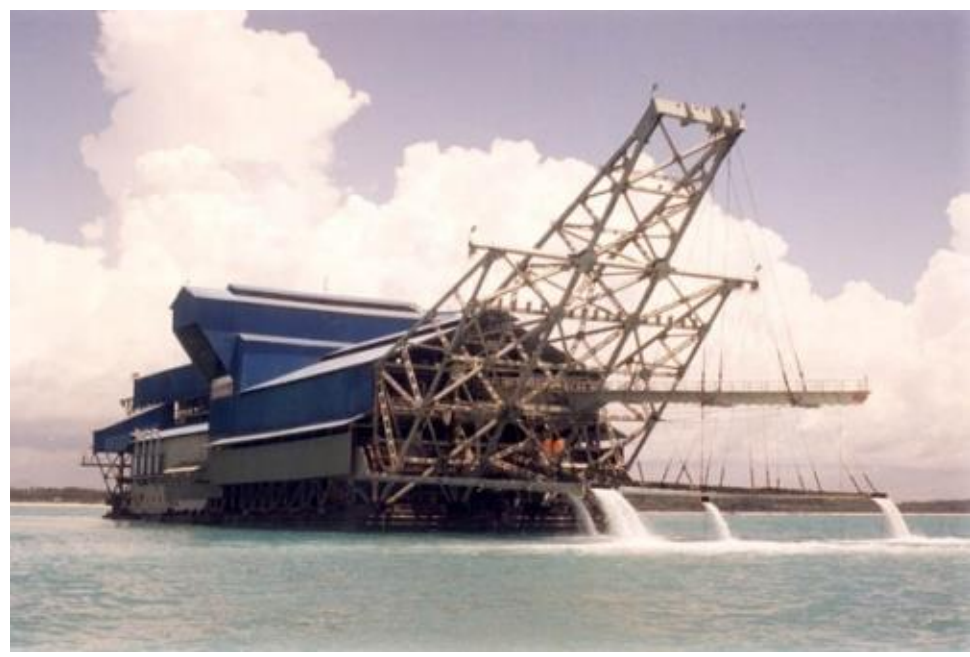

Gambar 1. Kapal Keruk Timah (Lepas Pantai)

Sumber: Google Image, 2021

Sedangkan penambangan timah darat sendiri dilakukan dengan cara menggali tanah menggunakan pompa semprot yang mengganti lapisan tanah subur (top soil) menjadi tanah pasir yang seharusnya berada di lapisan bawah. Pasir beserta biji timah dialirkan melalui peralatan yang disebut sakan untuk memisahkan timah dari pasir (Ibrahim, 2015). Pada awalnya penambangan timah hanya dilakukan di daratan Bangka Belitung, namun karena hasilnya semakin merosot dan biaya operasional yang semakin meningkat, penambangan timah juga dilakukan di laut.

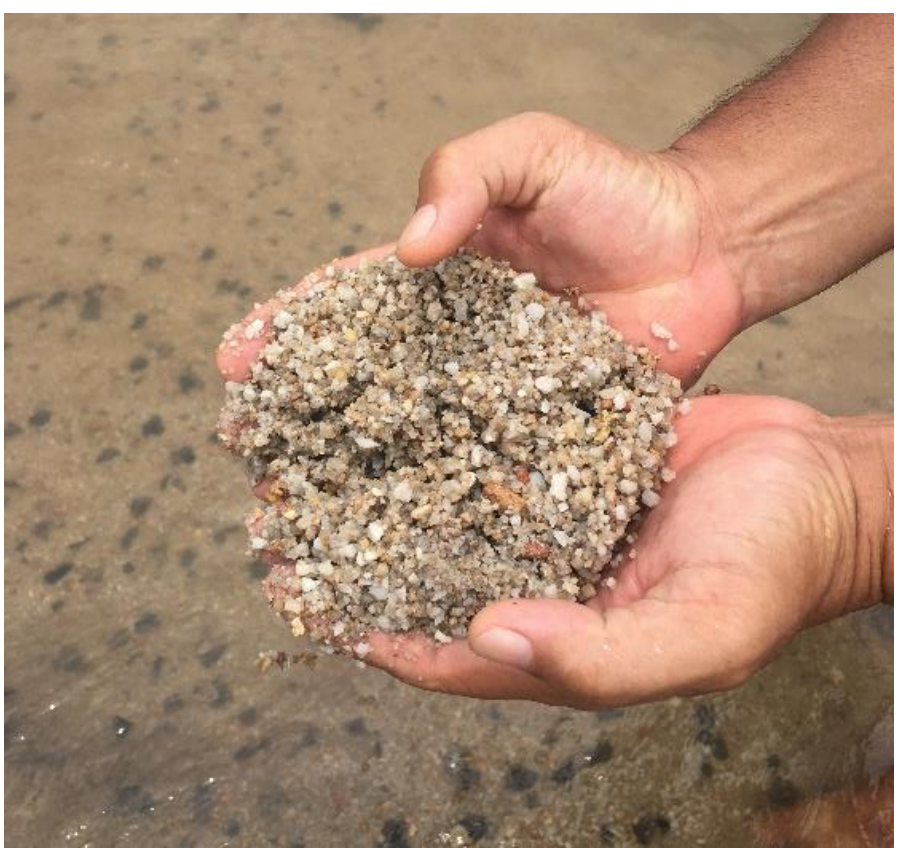

Gambar 2. Tanah di Lahan Pasca Tambang Timah (Darat) Sumber: Dokumentasi Pribadi, 2021 


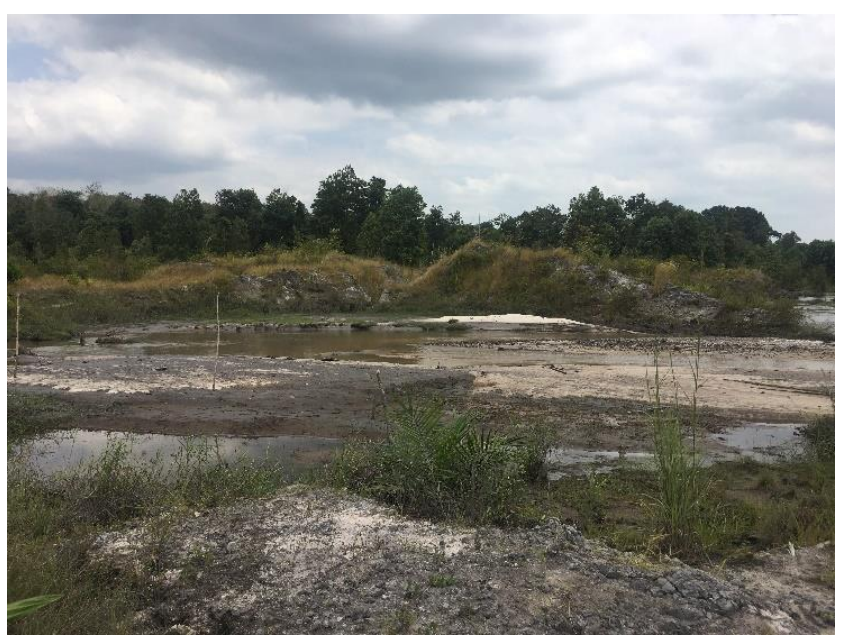

Gambar 3. Lahan Pasca Tambang Timah (Darat)

Sumber: Dokumentasi Pribadi, 2021

\section{Dampak pada Manusia}

Penambangan timah di Bangka melibatkan PT. Tambang Timah dan banyak lapisan masyarakat. Namun dalam prosesnya, munculah kesenjangan sosial antara penduduk lokal dan karyawan perusahaan. Hal tersebut menyebabkan penduduk lokal ingin mengambil alih hasil buminya sehingga banyak penduduk yang membuka tambang rakyat (Ibrahim, 2015). Kegiatan penambangan timah menyebabkan perubahan lanskap, kehilangan biodiversitas, kehilangan lapisan top soil, rendahnya status kesuburan tanah, serta pencemaran air dan sungai dengan logam berat (Meyzilia, 2018). Hal ini menyebabkan berbagai hal mulai dari penurunan kegiatan ekonomi dan vitalitas sebuah daerah. Sungai, tanah dan laut yang tercemar menyebabkan pekerjaan petani, peternak dan nelayan harus berhenti dan beralih menjadi penambang. Dalam salah satu wawancara dengan para penambang juga diketahui anak usia sekolah sebagian besar memilih untuk bekerja membantu orang tua di tambang dari pada melanjutkan sekolahnya (Dedi, 2015). Lahan tambang yang sudah terbengkalai juga tidak banyak bisa dipulihkan, sehingga berhektar-hektar lahan terbuka dengan harga jual tanah yang rendah, kehilangan daya tarik, serta topografi dan iklim mikro yang buruk tidak memungkinkan terjadinya perkembangan walaupun hanya untuk permukiman.

\section{Dampak pada Ekosistem Eksisting}

Lahan pasca tambang timah didominasi oleh hamparan tailing dan kolong. Kolong merupakan danau yang tercipta dari lubang raksasa hasil dari penggalian dan pompa semprot, sedangkan tailing adalah hamparan tanah di sekitar kolong hasil dari penggalian yang merupakan lapisan berpasir yang aslinya terletak di bawah tanah subur. Kolong memiliki karakteristik fisika dan kimia tanah, serta kondisi iklim mikro yang buruk. Aktvitas penambangan timah secara nyata telah mengubah lanskap menjadi tidak beraturan, berupa tumpukan tailing pasir dan kolong air. Tinggi gundukan tailing mencapai 3-8 $\mathrm{m}$ dari permukaan tanah. Terjadinya penurun kualitas tanah dan jumlah jenis vegetasi di lokasi hutan asli. Suhu asli memiliki rata-rata $27-31^{\circ} \mathrm{C}$ dan kelembaban $79-100 \%$, sedangkan di lokasi lahan pasca penambangan timah suhu rata-rata $42-$ $45^{\circ} \mathrm{C}$ dan kelembaban $35-40 \%$. Rendahnya produktivitas lahan tersebut disebabkan oleh buruknya sifat fisik, kimiawi dan biologi tanah (Asmarhansyah, 2017).

Kualitas air di kolong juga menjadi permasalahan yang krusial karena banyaknya kandungan logam berat seperti timbal $(\mathrm{Pb})$, Seng $(\mathrm{Zn})$, dan tembaga $(\mathrm{Cu})$ karena timah di alam tidak berdiri sendiri namun banyak diikuti jenis logam-logam lainnya. Kandungan logam berat ini dapat 
berkurang seiring berjalannya waktu namun memerlukan 20 tahun untuk benar benar bisa digunakan atau kolong memiliki akses ke laut dan sungai (Meyzilia, 2018).

\section{Sistem Penanganan}

Disinilah kemampuan manusia menjadi penting untuk menjaga keadaan alam yang lestari sebagaimana mestinya, yaitu Build Back Better. Build Back Better merupakan sebuah paradigma yang umumnya digunakan pada pemulihan pascabencana. Tujuannya ialah memulihkan kondisi yang rentan dan mentransformasikannya ke arah yang lebih baik. Paradigma ini diperkenalkan di dalam UN Sendai Framework for Disaster Risk Reduction 2015-2030. Pembangunan dengan menitik beratkan bukan lagi kepada sudut pandang sumber daya itu secara harafiah namun juga pembangunan yang mengedepankan value (Muhammad, nationalgeographic.grid.id/read/132449726, 2020).

Perbaikan kualitas lahan bekas tambang timah mutlak dilakukan melalui peningkatan kandungan C-organik tanah yang bersumber dari bahan organic (kotoran hewan, sisa tanaman / jerami, pupuk hijau / legume, sampah kota, limbah industri dan kompos) dan bahan pembenah tanah dan pupu organic lainnya. Kolong bekas penambangan timah yang telah berusia lebih dari 20 tahun dan kolong itu penuh berisi air, maka air kolong tersebut aman untuk diminum dan ikan yang hidup di dalamnya dapat dimakan karena kolong tersebut telah mengalami pengendapan mineral ikutan selain timah, yaitu radiasi dari sifat radioaktif yang dimilikinya. Namun dapat berubah karenah pembongkaran kembali dan longsor, maka diperlukan adanya revitalisasi tepi kolong. (Asmarhansyah, 2017)

\section{METODE}

Metode penelitian yang digunakan adalah penelitian kualitatif dengan memperhatikan aspek rancangan metode kolase sebagai metode desain. Metode kolase sendiri bertujuan untuk membuat setiap sudut dalam desain merangsang visual manusia (Sutanto, 2020). Kolase di bawah ini memuat kondisi tapak dan bagaimana bangunan bisa menyesuaikan diri dengan gambaran kondisi tersebut.

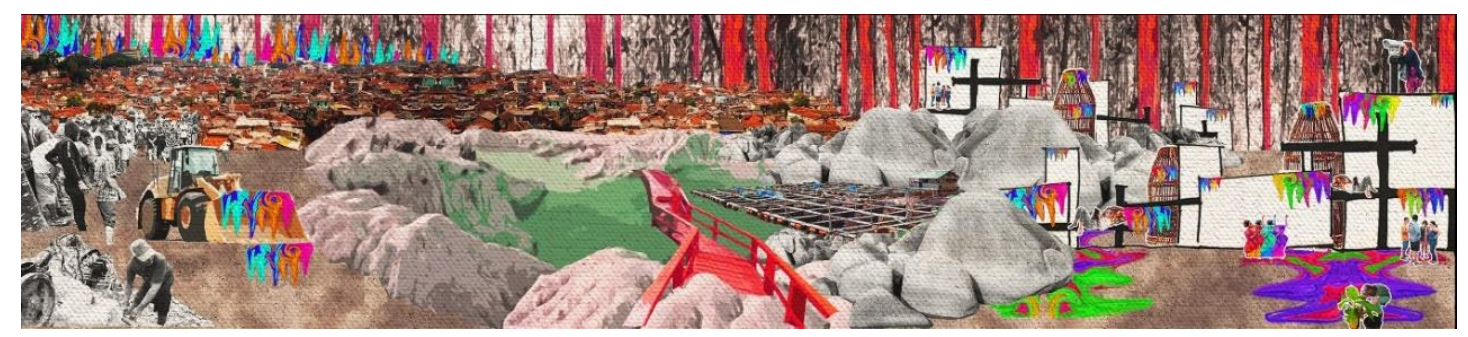

Gambar 4. Kolase Loka

Sumber: Dokumentasi Pribadi, 2020

Sisi kiri menggambarkan tentang Man's Build, yaitu bagaimana kolong bercerita tentang manusia yang mengambil dan menguasai alam sampai mengakibatkan semakin menjauh dan hilangnya lingkungan natural di tengah masyarakat. Menyisakan permasalahan ekonomi, sosial dan ekologi yang mengikuti selama adanya pertambangan timah.

Pada sisi kanan, menggambarkan tentang The Take Over, yaitu keadaan kolong berkesan seperti alam tidak bisa mengambil atau memulihkan dirinya sendiri lagi. Proyek ini bertujuan untuk dapat membuat manusia merasa kecil dan bangunan seakan membantu alam untuk mengambil apa yang semula miliknya, dengan memberikan medium untuk memulihkan dampak sosial, ekonomi dan ekologi yang terjadi selama adanya pertambangan timah. 
Di dalam kolase tersebut terdapat beberapa unsur untuk mewujudkan gagasan utama dari desain, diantaranya adalah bentuk geometris, bentuk organik, material yang akan digunakan, vegetasi, pengaturan skala dan rasa, sequence, connection dan aktifitas di dalam tapak.
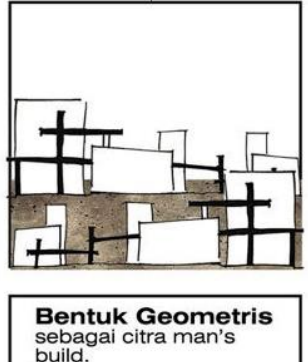
build.

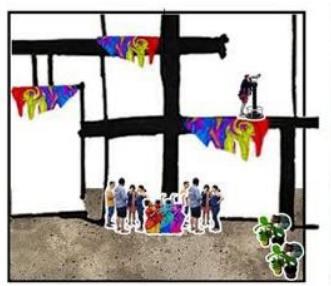

Skala dan Rasa Pengolahan skala bangu
nan terhadap manusia
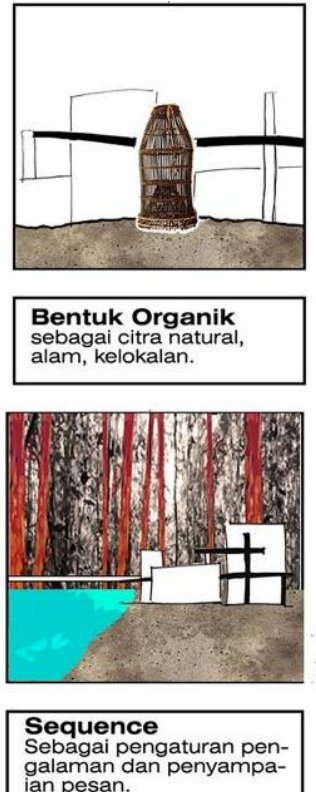
galaman dan penyampaan pesan.
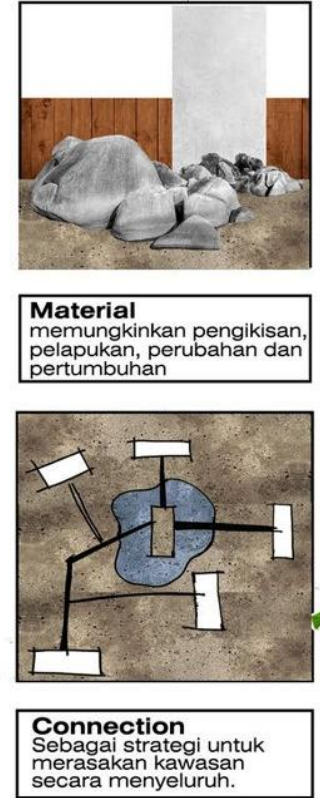

merasakan kawasan
secara menyeluruh.

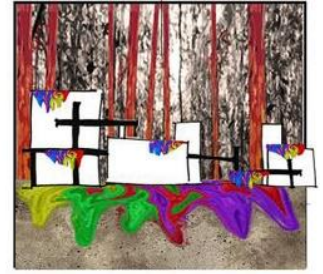

Vegetasi Pelestarian vegetasi lokal
dan kemungkinan tumbuh untuk vegetasi lain.

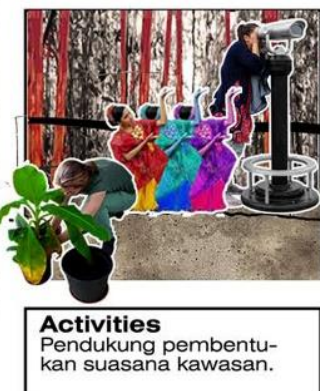

Gambar 5. Unsur Kolase Loka

Sumber: Dokumentasi Pribadi, 2021

\section{DISKUSI DAN HASIL}

Tapak berada di Jl. Pangkal Pinang-Muntok, Belo Laut, Muntok, Bangka Barat. Tapak memiliki aksesibilitas tinggi. Di kelilingi oleh Jl. Pangkal Pinang Muntok (jalan arteri), Jl. RSUD Ranggem (jalan menuju area pesisir), Jl. Komplek Pemda (jalan menuju area pesisir). Hal ini memudahakan akses untuk semua user. Area hijau disekitar tapak didominasi oleh perkebenunan sawit dan semak belukar. Banyak kebun terbengkalai karena tercemarnya tanah disekitarnya. Memungkinkan tapak berasa di dekat tempat tinggal petani dan peternak. Area permukiman warga mengelilingi tapak, menjadikan tapak sebagai pusat pertemuan dari semua kalangan masyarakat Muntok yang akan menjadi tuan rumah dari proyek ini.

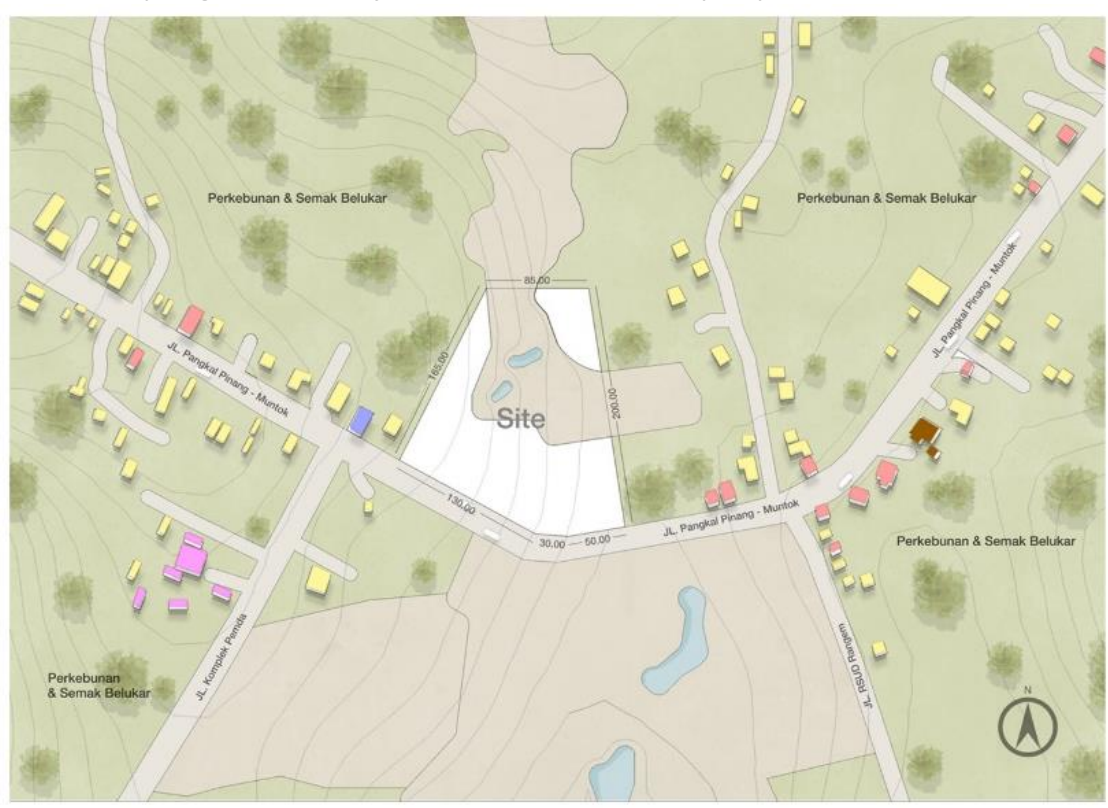

Gambar 6. Eksisting Lokasi Tapak dan Sekitarnya Sumber: Dokumentasi Pribadi, 2021 
Strategi desain diawali dengan eksisting tapak seluas $22.724 \mathrm{M}^{2}$ terdiri dari dua buah kolong, hamparan lahan tailing dan sisa lahan yang masih hijau dan subur (Gambar 7). Selanjutnya, pemulihan kolong menggunakan Passive Treatment System, yang berbentuk kolam limestone yang dapat menghasilkan alkalin guna menurunkan kadar logam. Kolam juga dibuat berkelokkelok untuk menghambat aliran air agar logam di dalam air punya waktu untuk mengendap (Gambar 8).

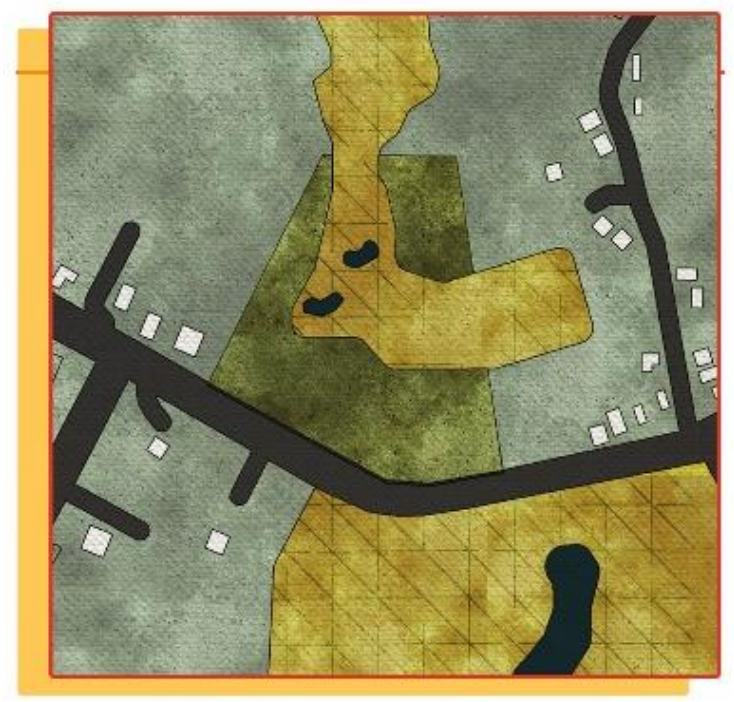

Gambar 7. Eksisting Tapak

Sumber: Dokumentasi Pribadi, 2021

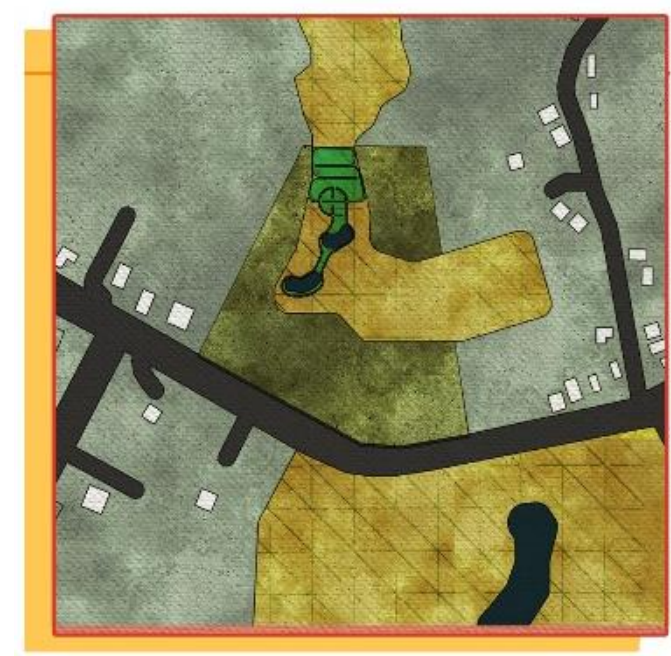

Gambar 8. Passive Treatment System

Sumber: Dokumentasi Pribadi, 2021

Selanjutnya meletakan zoning tapak berdasarkan kemudahan akses para penggunanya sesuai dengan activities, movement, dan faktor site thinking lainnya. Kawasan ini berlaku sebagai medium untuk memulihkan keadaan sosial, ekonomi dan ekologi yang terdampak selama adanya pertambangan timah. Loka sendiri terdiri dari 3 macam zoning, yaitu ekonomi dimana kegiatan transaksi jual beli warga terjadi melalui pasar pagi dan malam, zoning kedua adalah social dimana warga dapat berkumpul untuk melakukan kegiatan komunitas seperti upacara adat, zoning ketiga adalah ekologi dimana warga dapat kembali berternak dan bertani serta melakukan observasi terhadap lingkungannya. Dilengkapi dengan system pertanian terintegrasi dan upaya untuk pengembalian unsur hara tanah dan air dengan passive water treatment dan biogas plant. Secara keseluruhan gubahan massa berbentuk dasar geometris untuk menunjukan 
faktor man's build dalam tapak. Penyusunan letak massa mengusahakan Kolong menjadi highlight utama dalam tapak (Gambar 9). Pada penataan massa final, membaur keformalan dalam tapak yang dihasilkan dari bentuk geometris tersebut dan pembangunan sesuai kaidah arsitektur tropis (Gambar 10).

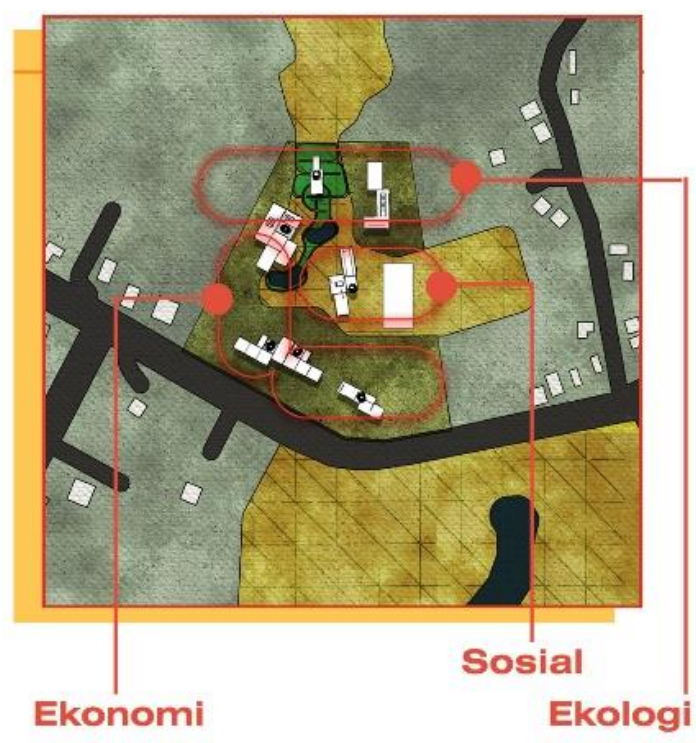

Gambar 9. Zoning

Sumber: Dokumentasi Pribadi, 2021

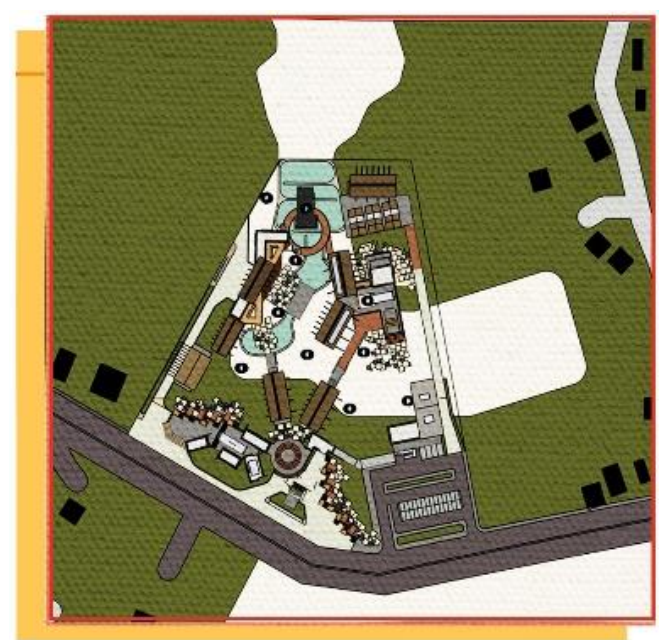

Gambar 10. Final Massing

Sumber: Dokumentasi Pribadi, 2021

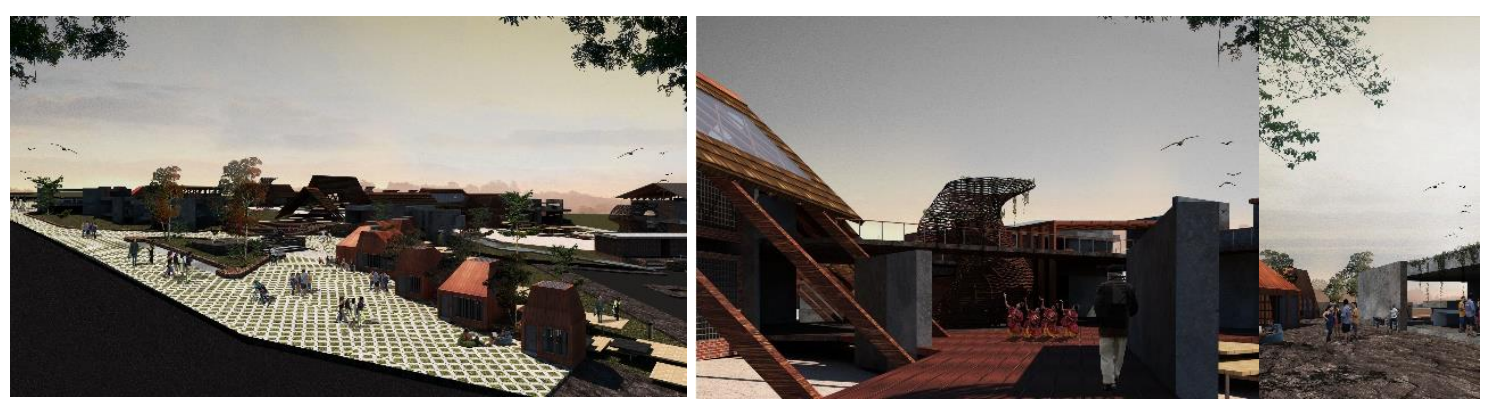

Gambar 11. Perspektif

Sumber: Dokumentasi Pribadi, 2021 
Proyek ini juga mengusung beberapa faktor dari Beyond Ecology yaitu: (1) Energy and Emission: Pembentukan massa yang mampu menerapkan zero $\mathrm{CO} 2$ dan pengurangan efek karbon, terutama dalam pengudaraan dan pencahayaan, (2) Adaptation and Resillience: Bangunan ini mampu memulihkan lahan pasca tambang timah di Bangka menjadi sebuah kawasan yang menghasilkan, menguntukan dan menyadarkan. Menggunakan Passive Treatment System untuk mengolah air dan kadar asam tanah. (3) New Technology: Tanaman yang tidak dapat tumbuh lagi di lahan tailing yang begitu luas dapat tumbuh di media rambat. Daun daun kering yang dihasilkan media rambat ini juga akan dimanfaatkan sebagai bahan organik untuk mengembalikan unsur hara tanah (kompos). (4) Context: Mempertimbangkan aspek flora dan fauna, hubungan dengan permukiman dan aktivitas di sekitar tapak, serta potensi tapak. Semua hal tersebut diterapkan pada program dan massing.

\section{KESIMPULAN DAN SARAN Kesimpulan}

Lahan tailing dan kolong pasca tambang timah terbengkalai menimbulkan banyak permasalahan ekonomi, social, dan ekologi bagi masyarakat Belo Laut. Dengan memberi peluang untuk mengambil alih tanah yang sudah dieksplotasi sebelumnya, perancangan Rumpun Terintegrasi Kultur dan Agrari ini dapat menjadi solusi untuk pemanfaatan kembali.

Segi ekonomi akan terbantu dengan adanya peternakan sapi, pasar yang dapat digunakan warga untuk menjual hasil melaut, bertani, peternakannya dari sekitar tapak, warga juga dapat memanfaatkan puja sera untuk mengolah pangan baik dari pasar ataupun hasil bumi sekitar tapak, mengingat proyek ini juga merupakan wadah untuk turis dan warga lokal berinteraksi. Segi sosial akan terbantu dengan adanya community hall dan pavillion, sebagai pusat penyelenggaraan upacara adat, festival, dan aktivitas sosial warga sehari-hari. Sedangkan passive water treatment, sistem biogas dan media rambat dapat dimanfaatkan untuk pemulihan ekosistem eksisting di dalam tapak yang merupakan lahan pasca tambang.

Rancangan bertema melampaui ekologi ini dapat memunculkan kembali rasa kagum manusia terhadap alam. Bangunan dapat membantu alam untuk mengambil alih apa yang semula miliknya. Bukan hanya dari segi program, namun segi massing bangunan juga memungkinkan terjadi perubahan, perusakan, pertumbuhan yang disebabkan oleh alam, seperti cuaca (panas dan hujan) dan pertumbuhan tanaman rambat. Dengan memenuhi faktor-faktor beyond ecology seperti: Energy and Emission, Adaptation and Resillience, New Techology, dan Context.

\section{Saran}

Dalam usaha untuk pemulihan lahan pasca tambang timah di Bangka, khususnya di desa Belo Laut, memerlukan partisipasi masyarakat lokal, pemerintah dan pengunjung dengan tetap mengusahakan pemanfaatan sumber daya alam yang sudah ada. Merawat dan memanfaatkan lahan yang sudah terbuka daripada membuka lahan baru, melakukan reklamasi dan revitalisasi lahan pasca tambang timah yang sudah tidak memungkinkan adanya daya tanam. Pemberdayaan masyarakat dan pengembalian hak masyarakat seperti pendidikan juga berpengaruh untuk kesuksesan pemulihan ekonomi, sosial dan ekologi daerah sekitar.

Secara keseluruhan rancangan dari kawasan ini perlu disempurnakan untuk meningkatkan efektifitasnya. Kawasan ini diharapkan dapat menghidupkan kembali kedinamisan dan vitalitas daerah serta menjadi acuan untuk studi lanjutan dengan tujuan yang sama. 


\section{REFERENSI}

Asmarhansyah. (2017). Inovasi Teknologi untuk Peningkatan Produktivitas Lahan Bekas Tambang. 92-97.

Bratton, B. H. (2015). The Stack: On Software and Sovereignty. London: Massachusetts Institute of Technology.

Dedi. (2015, December 8). INDONESIAKU - DERITA DIBALIK TIMAH BANGKA. (M. Noeva, Interviewer)

Hotimah, O. (2015). POTENSI EKONOMI PADA KOLONG BEKAS PENAMBANGAN TIMAH. Jurnal IImiah Mimbar Demokrasi, 87.

Ibrahim, I. (2015). Dampak Penambangan Timah Ilegal yang Merusak Ekosistem di Bangka Belitung. Selisik, 79.

Meyzilia, A. (2018). Pemanfaatan Air Kolong Bekas Tambang Timah sebagai Penambah Sumber Air Tanah menggunakan Lubang Kompos di Bangka Belitung. Jurnal Pendidikan IImu Sosial, 25-28.

Muhammad, F. (2020, Desember 2). nationalgeographic.grid.id/read/132449723. Retrieved from Nationalgeographic.co.id: https://nationalgeographic.grid.id/read/132449723/memulihkan-kembali-tambangtambang-timah-bangka-usai-eksploitasi?page=all

Muhammad, F. (2020, Desember 3). nationalgeographic.grid.id/read/132449726. Retrieved from Nationalgeographic.co.id: https://nationalgeographic.grid.id/read/132449726/cerita-kolong-timah-bangka-dimasa-lalu-sampai-masa-sekarang?page=all

Pedoman Mata Kuliah Studio Perancangan Arsitektur 8.31. (2021). 'MELAMPAUI' EKOLOGI MENUJU ARSITEKTUR UNTUK KEBAIKAN DAN KEHIDUPAN. Program Studi Sarjana Arsitektur Jurusan Arsitektur dan Perencanaan Fakultas Teknik Universitas Tarumanagara.

RIPPARPROV Kep. Bangka Belitung 2016 -2025 . (2015, Desember). LAPORAN AKHIR RENCANA INDUK PEMBANGUNAN KEPARIWISATAAN PROVINSI KEPULAUAN BANGKA BELITUNG. Bandung, Jawa Barat, Indonesia: Dinas Kebudayaan dan Pariwisata Provinsi Kepulauan Bangka Belitung.

Ryn, S. V., \& Cowan, S. (2007). Ecological Design, Tenth Anniversary Edition. Washington, DC: Island Press.

Sutanto, A. (2020). Peta Metode Desain. Universitas Tarumanagara: Jakarta

WALHI. (2017). Presiden, Segera Moratorium Tambang Timah Bangka Belitung! Jakarta: WALHI Nasional.

Yulianti, Bani, B., \& Albana. (2020). Analisan Pertambangan Timah di Provinsi Kepulauan Bangka Belitung. Jurnal Ekonomi, 58. 
